Bartın Üniversitesi

Eğitim Fakültesi Dergisi

Cilt 6, Sayı 3, s. 955-966, Ekim 2017

BARTIN - TÜRKIYE

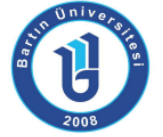

ISSN: 1308-7177
Bartin University

Journal of Faculty of Education

Volume 6, Issue 3, p. 955-966, October 2017

BARTIN - TURKEY

\title{
Üst Bilişsel Farkındalık Ölçeği Öğretmen Formunun Geçerlilik ve Güvenirlik Analizi
}

Elif ESMER, Dr., Marmara Üniversitesi, Atatürk Eğitim Fakültesi, esmerelif@gmail.com

ORCID: http://orcid.org/0000-0003-0264-3950

Alper YORULMAZ, Arş. Gör., Muğla Sıtkı Koçman Üniversitesi, Eğitim Fakültesi, alperyorulmaz07@gmail.com

ORCID: http://orcid.org/0000-0003-2832-6793

Öz: Bu araştırmanın amacı Sperling vd. (2002) tarafından geliştirilmiş Karakelle ve Saraç (2007) tarafından Türkçe'ye uyarlaması yapılan Çocuklar İçin Üst Bilişsel Farkındalık Ölçeğinin (A Formu) Öğretmen Formunu uyarlamak, ölçeğin geçerlik ve güvenirlik analizlerini yapmaktır. Üst Bilişsel Farkındalık Ölçeği A formu 12 madden oluşmakta olup 3.,4. ve 5. sınıf öğrencilerine yönelik hazırlanmış toplam puan üzerinden analiz yapılan bir ölçektir. Araştırmanın verileri İstanbul il merkezinde yer alan dört farklı okulda altı öğretmen tarafından 121 ilkokul öğrencisinin değerlendirilmesi ile toplanmıştır. Üst Bilişsel Farkındalık Ölçeği'nin geçerlik ve güvenirlik çalışmaları kapsam geçerliği için uzman görüşü alınmış, kriter geçerliliğini için Pearson korelasyon analizi, yapı geçerliği için açımlayıcı faktör analizi yapılmışır. Ölçeğin güvenirliğinin test edilmesi amacıyla madde toplam analizi, madde ayırt ediciliği ve test-tekrar test analizleri yapılmışır. Araştırma sonucunda elde edilen tüm bulgular değerlendirildiğinde geliştirilen Üst Bilişsel Farkındalık Ölçeği Öğretmen Formu ilkokul 3., 4. ve 5. sınıf öğrencilerinin üst bilişsel farkındalık düzeylerini belirlenmesi amacıyla kullanılabilecek geçerli ve güvenilir bir ölçme aracı olduğu tespit edilmiştir.

Anahtar Kelimeler: üstbiliş, farkındalık, ilkokul, öğretmen, öğrenci

\section{Reliability and Validity Analysis of the Metacognitive Awareness Scale Teacher Form}

\begin{abstract}
The purpose of the current study is to adapt and conduct reliability and validity analyses of the Metacognitive Awareness for Children Scale (A Form) Teacher Form developed by Sperling et al. (2002) and adapted to Turkish by Karakelle and Saraç (2007). The Metacognitive Awareness Scale A Form comprised of 12 items was prepared for 3 th, $4^{\text {th }}$ and $5^{\text {th }}$ grade elementary school students and analyses of the data collected from the scale are made on the total score. The data of the study were collected through the evaluation of 121 elementary school students by six teachers from four different schools located in the city of istanbul. In order to establish the content validity of the Metacognitive Awareness Scale, expert opinions were sought; Pearson correlation analysis was run for criterion validity and for construct validity, exploratory factor analysis was conducted. In order to test the reliability of the scale, total item correlation analysis, item discrimination analysis and test-retest analysis were performed. When all the findings of the study are evaluated, it can be argued that the Metacognitive Awareness Scale developed in the current study can be used as a reliable and valid tool to determine the metacognitive awareness level of the $3^{\text {rd }}, 4^{\text {th }}$ and $5^{\text {th }}$ grade elementary school students.
\end{abstract}

Key Words: metacognition, awareness, elementary school, teacher, student 


\section{GíRiş}

Üst biliş kavramı 1970'li yılların ortalarında John Flavell tarafından literatüre kazandırımıştır (Yore ve Treagust, 2006). Flavell, öğrencilerin yeterli ön bilgi ve stratejiye sahip olmalarına karşın problemleri çözemedikleri sorunundan hareket etmiş üst hafıza kavramını genişleterek üst biliş terimini kullanmaya başlamıştır (Yürük, 2014). Son 40 yıldır dünyada birçok araştırmaya konu olan "metacognition" kavramı ülkemizde 2000'li yılların başından itibaren tartışılmaya başlanmıştır. "Metacognition" kavramı Türkçe literatüründe üst biliş, biliş ötesi, yürütücü biliş, biliş bilgisi, öz düzenleyici, öz bilinç olarak adlandırılmıştır (Doğan, 2013). Türkçe literatürde kavram karmaşasını önlemek için bu çalışmada Türk Dil Kurumu tarafından karşılık olarak verilen üst biliş kelimesi kullanılmıştır.

Üst biliş, bilişsel süreçlerin farkında olma, süreci izleme, denetleme ve düzenlemeyi sağlayan işlemleri ifade etmek için kullanılan bir terimdir (Flavel, 1987; Brown, 1987; Sungur ve Şenler, 2009; Karakelle, 2012; Vrieling vd., 2012). Flavel'e (1979) göre üst biliş, iletişim, ikna etme, okuduğunu anlama, yazma, dil öğrenme, dikkat, bellek, problem çözme, sosyal biliş, özkontrol ve öz-öğretimin çeşitli alanlarında önemli bir rol oynamaktadır. Üst-biliş, daha geniş anlamda, kendi düşünme süreçlerine ilişkin farkındalık ve bu süreçleri kontrol etme becerisi olarak tanımlanabilen, biliş hakkındaki düşünce veya düşünceyi düşünmeye yönelik bir kavramdır (Karakelle ve Saraç, 2010; Özsoy, 2008). Bireyin kendi düşünme süreçlerinin farkında olması ve bu süreçleri kontrol altında tutarak yönlendirebilmesi üst biliş kavramı içerisinde yer almaktadır (Sarı, 2015). Zeka, hafıza ve çevresel faktörlerle ilişkili geliştirilebilir bir olgu olan üst biliş, öğrenme sürecinde yer alan bilişsel süreçlere ilişkin farkındalık yaratan, bu süreçlerin bilinmesini ve etkin kullanılmasını içeren zihinsel bir yeti ve beceriler bütünüdür(Baltacı ve Akpınar, 2011). Üst bilişin çevre ile etkileşim içerisinde geliştirilebilir bir yeti olması öğrenme ve öğretme süreçlerinde dikkate alınan bir olgu olmuştur.

Birey üst bilişsel bilgiyi düşünmeyi ve öğrenmeyi düzenlemek için kullanılır (Karakelle ve Saraç, 2007). Öğrenmenin düzenlenme sürecinde yer alan planlama, izleme ve değerlendirme becerileri üst bilişsel beceri içerisinde yer alan üç temel beceridir (Vrieling, Bastianes ve Stijnen, 2012). Üst bilişsel becerilerin gelişimi zihinsel yeteneklerin gelişimi ile paralellik göstermekte olup (Alexander, Johnson, Freygang ve Scott, 2006), bu süreçte izleme ve değerlendirme becerileri planlama becerisinden sonra gelişmektedir (Veenman, Van HoutWolters ve Afflerbach, 2006). Üst bilişsel beceri gelişimi bir süreç içerisinde ve birbirini etkileyen basamaklar halinde gerçekleşmektedir.

Üst bilişin karmaşık bir olgu olması (Kane, Lear ve Dube, 2014), birçok araştırmacının üst bilişi açıklamaya ilişkin strateji, model ve sınıflama geliştirmesine sebep olmuştur (Flavel, 1979; Brown, 1987; Tobias ve Everson, 2002; Shimamura, 2008). Bu sınıflamalar, modeller arasında Flavel'a (1979) tarafından yapılan bir bireyin bilişsel faaliyetlerini üst bilişsel bilgi, üst bilişsel deneyimler, hedefler ve eylemler olmak üzere dört bileşen arasındaki etkileşim ile gerçekleştiğini ortaya koyan model etkili olmuştur. Flavell'den bu tarafa zihin teorisi çerçevesinde değerlendirilen üst biliş 3- 5 yaşlarından itibaren üst bilişsel bilgi olarak gelişmeye başlar (Karakelle ve Saraç, 2007). Üst bilişin diğer bileşenleri olarak düzenleme becerileri içerisinde yer alan deneyimler, hedefler ise çocuklarda 8-10 yaşlarından itibaren ortaya çıkan ve ömür boyu devam eden bir becerilerdir (Kuhn, 2000). Üst biliş, bir kişinin bir şeyi anlamasına ve bilişsel yeteneğini kontrol etmesine yardımcı olduğundan dolayı öğrencilerin üst bilişsel becerileri olabildiğince erken eğitilmelidir (Siswati ve Corebima, 2017).

Eğitimin kalitesini arttırmak ve öğrenme sürecindeki sorunları çözmek için öğrencilerin üst bilişsel becerilerinin güçlendirilmesi ve erken yaşlardan itibaren eğitilmesi önemlidir. Bunun yanında 21.yüzyılda küreselleşen dünyada rekabet edecek bireylerin yetiştirilmesi için üst 
bilişsel beceriler geliştirilmelidir (Siswati ve Corebima, 2017). Üst bilişsel yapılarını kullanan öğrencilerin diğer öğrencilere göre daha çok bilgiye sahip olup, daha fazla ve uzun süre bilgiyi sakladıklarından kaynaklı olarak akademik başarıları üzerinde üst bilişsel becerilerin geliştirilmesi etkilidir (Woolfolk, 1998; Young ve Fry, 2008; Coutinho ve Neuman, 2008). Üst bilişsel beceriler öğrencilere öğretilecek dersler olarak değil belli konulara entegre edilerek verilmelidir (Pintrich, 2002). Eğitimciler öğretme öğrenme süreci boyunca öğrencilerinin üst bilişsel becerilerinin nasıl ne şekilde öğretileceğini ve geliştirileceğini bilmelidir (Siswati ve Corebima, 2017). Üst bilişsel becerilerin nasıl öğretileceği ve geliştirileceğinin belirlenmesi sürecinde öğrencilerin üst bilişsel yapılarının ölçülmesine gerek duyulmaktadır.

Üst bilişsel süreçlerin ölçülmesi amacıyla görüşme, yüksek sesle düşünme protokolleri, öğretmen görüşleri, izleme kontrol listeleri, kalibrasyon teknikleri ve envanterler gibi teknikler kullanılmaktadır (Karakelle ve Saraç, 2007). Ancak özellikle küçük yaşta öğrenim gören ilkokul öğrencilerinin üst bilişsel becerilerinden farkında oldukları beceriler gözlemlenebilir (Kramarski ve Mizrachi, 2004). Üst bilişe ilişkin yapılan çalışmalarda kullanılan ölçme araçlarına bakıldığında uluslararası literatüründe çocuklar için geliştirilen pek çok ölçme aracının (Jacobs ve Paris, 1987; Schraw ve Denison, 1994; Pereira-Laird ve Deane, 1997; Mokhtari ve Reichard, 2002; Sperling, Howard, Miller ve Murpy, 2002; Annevirta, Laakonen, Kinnunen ve Varuas, 2007; Lecce, Zocchi, Pagnin, Palladino ve Taumoepeau, 2010) olduğu görülmektedir. Türkiye'de üst bilişsel farkındalıkları belirlemeye yönelik ölçme araçlarının sınırlı (Çetinkaya ve Erktin, 2000; Abacı, Çetin ve Akın, 2006; Karakelle ve Saraç, 2007; Öztürk, 2012) olup bunların içerisinde de öğretmenin değerlendirme yapabildiği ölçme aracı bulunmamaktadır. Ayrıca ilkokul öğrencilerinin kendilerini değerlendirmeye ilişkin güvenilir bilgilere sahip olmadıklarından üst bilişsel farkındalıklarını ölçmek mümkün olmamaktadır. Öğretmenlerin öğrencilerin doğal ortamlarında, farklı etkinlikler ve dersler sırasında gözlemlemesinden dolayı üst bilişsel farkındalık ölçeğinin öğretmen formuna ihtiyaç vardır. Bu düşüncelerden hareketle bu çalışmada tüm dünyada geçerliliği kanıtlanmış Sperling, vd. (2002) tarafından geliştirilen Karakelle ve Saraç (2007) tarafından Türkçe'ye uyarlaması yapılan Çocuklar İçin Üst Bilişsel Farkındalık Ölçeği (A Formu) temel alınarak Öğretmen Formunu uyarlamak, ölçeğin geçerlik ve güvenirlik analizlerini yapmak amaçlanmıştır.

\section{YÖNTEM}

\section{1. Çalışma Grubu}

Araştırma İstanbul il merkezinde yer alan Milli Eğitim Bakanlığına bağlı basit tesadüfi örneklem yöntemi ile belirlenen dört farklı ilkokulda, altı farklı sınıfta ilkokula devam eden 121 çocuğun öğretmenleri ile gerçekleştirilmiştir. Çalışmaya dahil olan 6 öğretmenin 4'ü kadın, 2'si erkek; mesleki kıdemleri 5 yıl ve üzeri; öğrenim durumlarına ise 2'si lisansüstü, 4'ü lisanstır. Araştırmaya katılan öğrencilerin 56 'sı $(\% 46,3)$ kız, 65’i $(\% 53,7)$ erkek; öğrenim seviyeleri ise ilkokul dördüncü sınıftır.

\subsection{Veri Toplama Aracı}

Araştırmada veri toplama aracı olarak öğrenci hakkındaki bilgileri elde etmek için öğrencinin sınıf seviyesini ve cinsiyetini belirlemeye yönelik bilgi formu, çocukların üst bilişsel farkındalıklarını belirlemek amacıyla Üst Bilişsel Farkındalık Öğretmen Formu kullanılmıştır.

Üst Bilişsel Farkındalık Öğretmen Formu (ÜBFÖF): Üst bilişsel farkındalık ölçeği öğrencilerin üst bilişsel becerilerini ölçmek amacıyla Sperling, vd. (2002) tarafından geliştirilen Üstbilişsel Farkındalık Envanteri temel alınarak A ve B olmak üzere iki form halinde hazırlanmıştır. Üstbilişsel farkındalık envanteri Türkçe'ye Karakelle ve Saraç (2007) tarafından uyarlaması yapılmıştır. A formu 3., 4. ve 5. sınıf öğrencileri için 12 madde, B formu 6., 7., 8. ve 
9. sınıf öğrencileri için 18 maddeden oluşmaktadır. Araştırmamız çerçevesinde küçük yaş gruplarına ilişkin olarak hazırlanan A formunun, öğretmen formu üzerinden çalışma yürütülmüştür. Bu çerçevede $A$ formu 12 maddeden oluşmakta olup, her madde için üçlü likert tipi (her zaman, bazen, hiçbir zaman) ölçek üzerinden işaretlenmektedir. A formu için ölçekten alınabilecek en yüksek puan 36 , en düşük puan ise $12^{\prime}$ dir. Türkçe'ye uyarlanan ölçeğin A formu için iç tutarlııı güvenirliği .64, yapılan faktör analizi sonucunda varyansın \%48.49'unu açıklayan dört faktörlü bir yapı ortaya çıkmıştır. Ancak $A$ formunun faktör yapısı incelendiğinde iki faktöre toplanan maddelerin bulunması, madde dağılımları arasında farklar olması nedeniyle ölçeğin tek bir genel faktöre yüklendiği sonucuna varılmıştır. Benzeri gerekçelerle orijinal ölçekte de tek toplam puan elde edilmesinin önerilmesinden dolayı tek boyut üzerinden kullanılması uygun görülmüştür (Karakelle ve Saraç, 2007).

Çocuklara ve öğretmenlere tesadüfen belirlenen ilkokul eğitimi veren dört kurum üzerinden ulaşılmıştır. Okul müdürleri ile iletişime geçilmiş ve okul müdürleri ile öğretmenlere araştırma hakkında bilgilendirici bir yazı gönderilmiştir. Uygulama için izin veren ve çalışmaya katılma konusunda ailelerinden onay alınan çocuklar araştırmaya dahil edilmiştir.

Üst Bilişsel Farkındalık Öğretmen Formunun oluşturulmasında Karakelle ve Saraç (2007) tarafından hazırlanan öğrencilere yönelik form alınmış soru kökleri ve yapıları değiştirilmiştir. Alanda uzman kişilerden görüşler alınmış fikir birliği ve ayrılığı doğrultusunda yorumları ve görüşleri alınarak öğretmen formunun son hali hazırlanmıştır. Uzman görüşü alındıktan sonra hazırlanan üst bilişsel farkındalık öğretmen formu ölçeğin kapsam geçerliliğinin incelenmesi ve doldurulması için geçen sürenin belirlenmesi amacıyla, ölçek 15 ilkokul öğretmen tarafından doldurulmuştur. ilkokul öğretmenlerinin yorumları alındıktan sonra, ölçeğin son hali çalışma kapsamında yer alan öğretmenlere gönderilmiştir. Sınıf öğretmenleri Üst Bilişsel Farkındalık Öğretmen Formunu ve demografik bilgi formlarını doldurmuş, bu formlar sınıf öğretmenlerinden araştırmacılar tarafından teslim alınmıştır.

\subsection{Verilerin Analizi}

Araştırma kapsamında geliştirilen Üst Bilişsel Farkındalık Ölçeği'nin geçerlik ve güvenirlik çalışmaları kapsamında öncelikle Marmara Üniversitesi Sınıf Eğitimi Anabilim Dalı'nda görev yapan 5 öğretim üyesinden uzman görüşü alınarak kapsam geçerliği sınanmıştır. Ölçeğin kriter geçerliliğini test emek amacıyla 31 öğrenci ile "Çocuklar İçin Üst Bilişsel Farkındalık Ölçeği" uygulanmış ve elde edilen veriler Pearson korelasyon analizi ile test edilmiştir. Üst Bilişsel Farkındalık Ölçeği'nin yapı geçerliğinin sınanması amacıyla ise açımlayıcı faktör analizi yapılmıştır.

Üst Bilişsel Farkındalık Ölçeği'nin güvenirliğinin test edilmesi amacıyla madde toplam analizi, madde ayırt ediciliği ve test-tekrar test analizleri yapılmıştır. Ölçeğin madde ayırt ediciliğini belirlemek amacıyla testin her bir maddesi için en yüksek puanın \%27'lik dilim puanları ile testin her bir maddesi için en düşük puanın \%27'lik dilim puanları arasında ilişkisiz $t$ testi ile karşılaştırılmıştır. Ayrıca Üst Bilişsel Farkındalık Ölçeği'nin 74 öğrenci ile yapılan testtekrar test sonuçları arasındaki ilişki için Pearson korelasyon analizi yapılmıştır.

\section{BULGULAR}

Bu bölümde araştırma kapsamında geliştirilen Üst Bilişsel Farkındalık Ölçeği Öğretmen Formu (ÜBFÖF) geçerlik ve güvenirliğine ilişkin elde edilen bulgular sunulmuştur.

Geliştirilen Üst Bilişsel Farkındalık Ölçeği Öğretmen Formu uzman değerlendirmeleri için Marmara Üniversitesi Sınıf Eğitimi Anabilim Dalı'nda görev yapan 5 öğretim üyesinden uzman görüşü alınmıştır. Uzman değerlendirmeleri sonucunda her bir madde için kapsam geçerlik oranı hesaplanmıştır. 
Tablo 1

Üst Bilişsel Farkındalık Ölçeği Öğretmen Formunun Uzman Görüşlerine ilişskin Kapsam Geçerlik Oranı

\section{Maddeler}

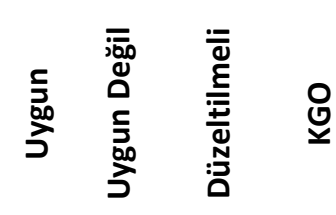

M1- Bir şeyi anlayıp anlamadığını bilir.

M2- İhtiyacı olduğunda kendi kendine öğrenebilir.

$\begin{array}{llll}5 & 0 & 0 & 1 \\ 5 & 0 & 0 & 1 \\ 5 & 0 & 0 & 1\end{array}$

M3- Daha önce işine yaramış olan çalışma yollarını kullanmaya gayret $\begin{array}{lllll}5 & 0 & 0 & 1\end{array}$ eder.

M4- Sınıfta işlenen konunun ne olduğunun farkındadır.

M5- Konu hakkında daha önceden bir şeyler biliyorsa daha iyi öğrenir.

M6- Şekil ve resimler çizmek bir konuyu daha iyi anlamasını sağlar.

$5 \quad 0 \quad 0 \quad 1$

M7- Çalışması sona erdiğinde öğrenmek istediği konuyu öğrenip

öğrenmediğine ilişkin olarak kendisini değerlendirir.

M8- Bir problemi çözmek için birçok yol düşünerek, aralarından en iyi $\begin{array}{lllll}5 & 0 & 0 & 1\end{array}$ olanını seçer.

M9- Çalışmaya başlamadan önce neye ihtiyacı olduğunu belirler.

M10- Yeni bir şey öğrenirken öz eleştiri yapar.

M11- Önemli bilgileri çok dikkatli dinler.

M12- İlgisini çeken konuları daha iyi öğrenir.

$$
\text { Uzman Sayısı }=5
$$

Kapsam Geçerlik Ölçütü= 0,99

Kapsam Geçerlik Indeksi= 1

Tablo 1'e göre beş alan uzmanı tarafından yapılan değerlendirme sonucunda Üst Bilişsel Farkındalık Ölçeği Öğretmen Formu kapsam geçerlik oranı tüm maddeler için 1 olarak belirlenmiştir. Ayrıca tüm test için Kapsam Geçerlik Indeksi hesaplanmıştır (KGI=1).

Geliştirilen Üst Bilişsel Farkındalık Ölçeği Öğretmen Formunun ölçüt geçerliliğini sağlamaya yönelik olarak kriter geçerliği kapsamında 31 öğrenci ile Çocuklar İçin Üst Bilişsel Farkındalık Ölçeği arasındaki ilişkinin incelendiği Pearson korelasyon analizi Tablo 2'de sunulmuştur.

Tablo 2

Üst Bilişsel Farkındalık Ölçeği Öğretmen Formu ile Çocuklar İ̧̧in Üst Bilişsel Farkındalık Ölçeği Arasındaki ilişkiye Yönelik Pearson Korelasyon Analizi

$\begin{array}{lll} & \mathbf{r} & , 359 \\ \text { Üst Bilişsel Farkındalık Ölçeği } & \mathbf{P} & , 047^{*}\end{array}$

Tablo 2 incelendiğinde Üst Bilişsel Farkındalık Ölçeği Öğretmen Formu puan ortalaması ile Çocuklar İçin Üst Bilişsel Farkındalık Ölçeği puan ortalaması arasında pozitif yönlü anlamlı ilişki olduğu saptanmıştır ( $r=.359 ; p<.05)$.

Üst Bilişsel Farkındalık Ölçeği Öğretmen Formunun yapı geçerliliğinin sınanması amacıyla yapılan açımlayıc faktör analizi sonuçları Tablo 3'te sunulmuştur.

Tablo 3

Üst Bilişssel Farkındalık Ölçeği Öğretmen Formunun Açımlayııı Faktör Analizine iliş̧in Sonuçlar

\begin{tabular}{llllllllllllll}
\hline Faktör 1 & M1 & M2 & M3 & M4 & M5 & M6 & M7 & M8 & M9 & M10 & M11 & M12 \\
\hline
\end{tabular}




\begin{tabular}{|c|c|c|c|c|c|c|c|c|c|c|c|}
\hline .843 & .787 & .824 & .805 & .691 & .577 & .831 & .825 & .804 & .846 & .826 & 691 \\
\hline \multicolumn{12}{|c|}{ Toplam Açıklanan Varyans Oranı= 61,34 } \\
\hline \multicolumn{12}{|c|}{$K M O=.904$} \\
\hline \multicolumn{12}{|c|}{ Barlett Sınaması Değeri $=1184,96 p=.000$} \\
\hline
\end{tabular}

Tablo 3'te görüldüğü gibi Üst Bilişsel Farkındalık Ölçeği Öğretmen Formunun 12 maddesinin tek bir faktör altında toplandığı belirlenmiştir. Bir faktörün ölçeğe ilişkin varyansı açıklama oranı \% 61,342'dir. Kabul edilebilir oranın \% 30 olduğu dikkate alındığında (Çokluk, Şekercioğlu, Büyüköztürk; 2014) elde edilen sonuçlar, ölçeğin bir faktöre sahip olduğunu göstermektedir. sunulmuştur.

Üst Bilişsel Farkındalık Ölçeği Öğretmen Formunun madde toplam analizleri Tablo 4'te Tablo 4

Üst Bilişsel Farkındalık Ölçeği Öğretmen Formunun Madde Toplam Analizleri

\begin{tabular}{lcccc}
\hline Madde No & $\begin{array}{l}\text { Madde Çıkartılırsa } \\
\text { Test Ortalaması }\end{array}$ & $\begin{array}{l}\text { Madde Çıkartılırsa } \\
\text { Test Varyansı }\end{array}$ & $\begin{array}{l}\text { Düzeltilmiş Madde- } \\
\text { Toplam Korelasyonu }\end{array}$ & $\begin{array}{l}\text { Madde Çıkartılırsa } \\
\text { Cronbach Alfa Değeri }\end{array}$ \\
\hline M1 & 25,91 & 26,53 &, 80 &, 93 \\
M2 & 26,44 & 25,75 &, 75 &, 94 \\
M3 & 26,06 & 25,99 &, 78 &, 93 \\
M4 & 25,84 & 26,89 &, 75 &, 93 \\
M5 & 25,65 & 28,20 &, 62 &, 94 \\
M6 & 25,58 & 29,43 &, 51 &, 94 \\
M7 & 26,38 & 25,95 &, 80 &, 93 \\
M8 & 26,39 & 24,81 &, 79 &, 93 \\
M9 & 26,69 & 25,47 &, 78 &, 93 \\
M10 & 26,59 & 24,94 &, 83 &, 93 \\
M11 & 25,88 & 26,69 &, 78 &, 94 \\
M12 & 25,62 & 28,70 &, 62 &, 93 \\
\hline
\end{tabular}

Test Toplam Cronbach Alfa Değeri = 0,94

Tablo 4'te Üst Bilişsel Farkındalık Ölçeği Öğretmen Formunun maddelerinin diğer maddelerin toplamından oluşan bütün arasındaki korelasyon incelenmiştir. Madde-toplam korelasyon değerlerine göre en düşük değerin 0,505 , en yüksek değerin ise 0,826 olduğu belirlenmiş ve madde-toplam korelasyon sonuçlarına göre hiçbir maddenin .20'nin altında değere sahip olmadığı saptanmıştır. Ayrıca madde çıkartılırsa Cronbach Alfa güvenirlik katsayısının değişimi incelendiğinde en düşük değerin 0,931, en yüksek değerin 0,942 ve test toplam Cronbach Alfa değerinin 0,940 olduğu belirlenmiştir. 
Üst Bilişsel Farkındalık Ölçeği Öğretmen Formunun madde ayırt ediciliğine ilişkin bulgular Tablo 5'de sunulmuştur.

Tablo 5

Üst Bilişsel Farkındalık Ölçeği Öğretmen Formunun Madde Ayırt Edicilikleri

\begin{tabular}{|c|c|c|c|c|c|c|c|}
\hline Madde & Grup & $\mathrm{n}$ & $\bar{X}$ & Ss & $t$ & Sd & $p$ \\
\hline \multirow[t]{2}{*}{ M1 } & Alt \% 27 & 33 & 1,90 & ,38 & \multirow{2}{*}{$-14,44$} & \multirow{2}{*}{64} & \multirow{2}{*}{$.000^{*}$} \\
\hline & Üst \% 27 & 33 & 2,96 & ,17 & & & \\
\hline \multirow[t]{2}{*}{ M2 } & Alt \% 27 & 33 & 1,15 & ,36 & \multirow{2}{*}{$-12,85$} & \multirow{2}{*}{64} & \multirow{2}{*}{$.000^{*}$} \\
\hline & Üst \% 27 & 33 & 2,54 &, 50 & & & \\
\hline \multirow[t]{2}{*}{ M3 } & Alt \% 27 & 33 & 1,69 &, 46 & \multirow{2}{*}{$-16,04$} & \multirow{2}{*}{64} & \multirow{2}{*}{$.000 *$} \\
\hline & Üst \% 27 & 33 & 3,00 & ,00 & & & \\
\hline \multirow[t]{2}{*}{ M4 } & Alt \% 27 & 33 & 1,93 & 42 & \multirow{2}{*}{$-14,21$} & \multirow{2}{*}{64} & \multirow{2}{*}{$.000^{*}$} \\
\hline & Üst \% 27 & 33 & 3,00 & ,00 & & & \\
\hline \multirow[t]{2}{*}{ M5 } & Alt \% 27 & 33 & 2,42 & ,70 & \multirow{2}{*}{$-4,67$} & \multirow{2}{*}{64} & \multirow{2}{*}{$.000 *$} \\
\hline & Üst \% 27 & 33 & 3,00 & ,00 & & & \\
\hline \multirow[t]{2}{*}{ M6 } & Alt \% 27 & 33 & 2,63 &, 54 & \multirow{2}{*}{$-3,81$} & \multirow{2}{*}{64} & \multirow{2}{*}{$.000 *$} \\
\hline & Üst \% 27 & 33 & 3,00 &, 00 & & & \\
\hline \multirow{2}{*}{ M7 } & Alt \% 27 & 33 & 1,39 &, 49 & \multirow{2}{*}{$-12,38$} & \multirow{2}{*}{64} & \multirow{2}{*}{$.000 *$} \\
\hline & Üst \% 27 & 33 & 2,78 &, 41 & & & \\
\hline \multirow{2}{*}{ M8 } & Alt \% 27 & 33 & 1,12 & ,33 & \multirow{2}{*}{$-18,99$} & \multirow{2}{*}{64} & \multirow{2}{*}{$.000 *$} \\
\hline & Üst \% 27 & 33 & 2,81 & ,39 & & & \\
\hline \multirow{2}{*}{ M9 } & Alt \% 27 & 33 & 1,03 & 17 & -1628 & 64 & $000 *$ \\
\hline & Üst \% 27 & 33 & 2,54 &, 50 & $-10,<0$ & 04 & .000 \\
\hline M10 & Alt \% 27 & 33 & 1,03 & 17 & -2012 & 64 & $000 *$ \\
\hline IVIO & Üst \% 27 & 33 & 2,72 &, 45 & $-\angle U, 12$ & 04 & .000 \\
\hline M11 & Alt \% 27 & 33 & 1,93 & ,42 & -14.22 & 64 & $.000 *$ \\
\hline IVIII & Üst \% 27 & 33 & 3,00 &, 00 & & 04 & .000 \\
\hline M12 & Alt \% 27 & 33 & 2,45 &, 56 & $-5,56$ & 64 & $000 *$ \\
\hline IVILL & Üst \% 27 & 33 & 3,00 &, 00 & ט, & 04 & .000 \\
\hline
\end{tabular}

Tablo 5 incelendiğinde Üst Bilişsel Farkındalık Ölçeği Öğretmen Formunun maddelerin ayırt ediciliğini belirlemek amacıyla testin her bir maddesi için en yüksek puanın \%27'lik dilim puanları ile testin her bir maddesi için en düşük puanın \%27'lik dilim puanları arasında ilişkisiz $t$ testi yapılmıştır. Analiz sonucunda, ölçeğin tüm maddeleri için alt ve üst gruplar arasında anlamlı farklılık olduğu bulunmuştur $(p<.05)$.

Üst Bilişsel Farkındalık Ölçeği Öğretmen Formunun test-tekrar test sonuçlarına ilişkin bulgular Tablo 6'da sunulmuştur.

Tablo 6

Üst Bilişsel Farkındalık Ölçeği Öğretmen Formunun Test-Tekrar Test Katsayıları

\begin{tabular}{ccc}
\hline & & Tekrar Test \\
\hline Test & $r$ &, 936 \\
& $p$ &, 000
\end{tabular}

Tablo 6 incelendiğinde Üst Bilişsel Farkındalık Ölçeği Öğretmen Formunun 74 öğrenci ile yapılan test-tekrar test sonuçları arasında anlamlı ilişki olduğu bulunmuştur $(p<.05)$. Buna göre Pearson korelasyon katsayısının .936 olduğu saptanmıştır. 


\section{SONUÇ, TARTIŞMA VE ÖNERILER}

Bu bölümde geliştiren Üst Bilişsel Farkındalık Ölçeği Öğretmen Formunun geçerlik ve güvenirliğine ilişkin elde edilen bulgular tartışılmıştır.

Üst Bilişsel Farkındalık Ölçeği Öğretmen Formunun ölçüt geçerliğinin belirlenmesi amacıyla ilk olarak 5 alan uzmanının görüşleri alınarak kapsam geçerliği test edilmiştir. Lawshe (1975)'e göre 5 uzman görüşü sonucunda testin maddelerinin alabileceği minimum değerin 0,99 olduğu ve bu değerden daha düşük değere sahip olan test maddelerinin testten çıkartılmasının uygun olduğu belirlenmiştir (Akt. Yurdugül, 2005). Ölçekte hiçbir maddenin kapsam geçerlilik oranı 0,99 değerinin altında kalmadığı için bütün maddeler korunmuş ve ölçeğin Kapsam Geçerlik İndeksi 1 olarak hesaplanmıştır. Bu sonuç ölçeğin kapsam geçerliğini sağladığını göstermektedir.

Ölçeğin kriter geçerliğini test etmek amacıyla Çocuklar İçin Üst Bilişsel Farkındalık Ölçeği arasındaki ilişki incelenmiştir. Üst Bilişsel Farkındalık Ölçeği Öğretmen Formu ile Çocuklar İçin Üst Bilişsel Farkındalık Ölçeği arasında pozitif yönde anlamlı ilişki olduğu saptanmıştır $(r=.359 ; p<.05)$. Buna göre geliştirilen ölçeğin kriter geçerliğini sağladığı ifade edilebilir.

Üst Bilişsel Farkındalık Ölçeği Öğretmen Formunun yapı geçerliliği sınamak amacıyla yapılan açımlayıcı faktör analizi sonuçlarına göre ölçeğin 12 maddesi tek bir faktör altında toplanmış ve bu faktörün ölçeğe ilişkin varyansı açıklama oranı \% 61,342 olduğu belirlenmiştir. Çokluk, Şekercioğlu ve Büyüköztürk (2014) bir ölçeğin varyansı kabul edilebilir açıklama oranını \% 30 olarak ifade etmişlerdir. Bu sonuç doğrultusunda ölçeğin yapı geçerliğini sağladığı görülmektedir.

Ölçeğin güvenirliğinin test edilmesi amacıyla iç tutarlılı̆ı belirlemek için Cronbach Alfa katsayısı hesaplanmıştır. Yapılan madde analizi sonucunda ölçeğin düzeltilmiş madde-toplam korelasyon değerleri arasında en düşük değerin 0,505 olduğu belirlenmiştir. Alan yazında ölçme araçlarının güvenirliğini arttırmak için madde katsayısı 0,20'nin altında olan maddelerin testten çıkarılması gerektiği ifade edilmiştir (Erkuş, 2014; Şeker ve Gençdoğan, 2014). Ancak madde ortalama ile test varyansları incelendiğinde hiçbir maddenin testten çıkarılmamasına karar verilmiştir. Ölçeğin toplam Cronbach Alfa değerinin 0,940 olduğu bulunmuştur ve bu değer, testin güvenirliğini kanıtlar niteliktedir (Büyüköztürk, 2014).

Üst Bilişsel Farkındalık Ölçeği Öğretmen Formunun maddelerin ayırt ediciliğini test etmek amacıyla, ölçeği oluşturan her bir maddenin en yüksek puan alan \%27'lik dilimi ile en düşük puan alan \%27'lik dilimi $\mathrm{t}$ testi analizi ile karşılaştırılmış ve tüm maddelerin ayırt edici olduğu saptanmıştır. Farklı zamanlarda alınan puanların tutarlıı̆ı̆ı belirlemek amacıyla Üst Bilişsel Farkındalık Ölçeği Öğretmen Formunun test-tekrar test güvenirliği kapsamında Pearson korelasyon katsayısının .936 olduğu saptanmıştır. Bu sonuç, testin zaman içindeki güvenirliği açısından önemli görülmektedir (Dede ve Yaman, 2008).

Araştırma sonucunda elde edilen tüm bulgular değerlendirildiğinde geliştirilen Üst Bilişsel Farkındalık Ölçeği'nin ilkokul 3, 4 ve 5. Sınıf öğrencilerinin üst bilişsel farkındalık düzeylerinin belirlenmesi amacıyla kullanılabilecek geçerli ve güvenilir bir ölçme aracı olduğu tespit edilmiştir. Üst bilişin öğretmen tarafından değerlendirilmesine yönelik olarak geliştirilen ölçeğin yapılacak çalışmalarla öğrencinin kendi değerlendirmesiyle karşılaştırılması, deneysel çalışmalarla üst biliş farkındalığının farklılaşma durumunun incelenmesi önerilmektedir. 


\section{KAYNAKLAR}

Abacı, R., Çetin, B. ve Akın, A. (2006). Biliş ötesi farkındalık envanteri: geçerlik ve güvenirlik çalışması. 14. Ulusal Psikoloji Kongresi Özet Kitapçığı, H.U., Ankara.

Alexander, J. M., Johnson, K. E., Albano, J., Freygang, T. ve Scott, B.(2006) Relations Between intelligence and the development of metaconceptual knowledge. Metacognition and Learning, 1, 51-67.

Annevirta, T., Laakkonen, E., Kinnunen, R. ve Vauras, M. (2007). Developmental dynamics of metacognitive knowledge and text comprehension skill in the first primary school years. Metacognition and Learning, 2, 21-39.

Baltacı, M. ve Akpınar, B. (2011). Web tabanlı öğretimin öğrenenlerin üstbiliş farkındalık düzeyine etkisi. Mustafa Kemal Üniversitesi Sosyal Bilimler Enstitüsü Dergisi, 8 (16), 319333.

Brown, A. (1987) Metacognition, executive control, self-regulation and other more mysterious mechanisms. In: Weinert, F.E., Kluwe, R.H. (Eds.) Metacognition, Motivation, and Understanding(pp. 65-116). Lawrence Erlbaum, Hillsdale.

Büyüköztürk, Ş. (2014). Sosyal Bilimler İçin Veri Analizi El Kitabı. 20. Baskı. Ankara: Pegem Akademi Yayıncılık.

Coutinho, S. A. ve Neuman, G. (2008). A model of metacognition, achievement goal orientation, learning style and self efficacy, Learning Environments Research, 11(2), 131151. DOI: $10.1007 / \mathrm{s} 10984-008-9042-7$.

Çetinkaya, P. ve Erktin, E. (2002) Assessment of metacognition and its relationship with reading romprehension, achievement, and aptitude. Boğaziçi Eğitim Fakültesi Dergisi, 19 (1), 111.

Çokluk, Ö., Şekercioğlu, G. ve Büyüköztürk, Ş. (2014). Sosyal Bilimler için Çok Değişkenli istatistik SPSS ve LISREL Uygulamaları.3. Baskı. Ankara: Pegem Akademi Yayıncılık.

Dede, Y. ve Yaman, S. (2008). Fen öğrenmeye yönelik motivasyon ölçeği: Geçerlik ve güvenirlik çalışması. Necatibey Eğitim Fakültesi Elektronik Fen ve Matematik Eğitimi Dergisi, 2(1), 19-37.

Doğan, A. (2013). Üstbiliş ve üstbilişe dayalı öğretim. Middle Eastern \& African Journal of Educational Research, 3, 6-20.

Erkuş, A. (2014). Psikolojide Ölçme ve Ölçek Geliştirme-I Temel Kavramlar ve Işslemler. 2. Baskı. Ankara: Pegem Akademi Yayıncılık.

Flavell, J.H. (1979). Metacognitive and cognitive monitoring: a new area of cognitive developmental inquiry. American Psychologist, 34, 906-911.

Flavell, J. H. (1987) Speculation about the nature and development of metacognition. In: Winert, F., Kluwe, R. (Ed.) Metacognition, Motivation, and Understanding (pp. 21-29). Lawrence Erlbaum, Hillsdale.

Jacobs, J. ve Paris, S. (1987). Children's metacognition about reading: Issues in defi nition, measurement and instruction. Educational Psychologist, 22 (3-4), 255-278.

Kane,S., Lear, M. ve Dube, C.M. (2014). Reflections on the role of metacognition in student reading and learning at higher education level, Africa Education Review, 11(4), 512-525. DOI: 10.1080/18146627.2014.935001 
Karakelle, S. (2012). Üst bilişsel farkındalık, zekâ, problem çözme algısı ve düşünme ihtiyacı arasındaki bağlantılar. Eğitim ve Bilim, 37(164), 237-250.

Karakelle, S. ve Saraç, S. (2007). Çocuklar için Üst Bilişsel Farkındalık Ölçeği (ÜBFÖ-Ç) A ve B formları: Geçerlik ve güvenirlik çalışması. Türk Psikoloji Yazıları, 10(20), 87- 103.

Karakelle, S. ve Saraç, S. (2010). Üst Biliş Hakkında Bir Gözden Geçirme: Üst Biliş Çalışmaları mı Yoksa Üst Bilişsel Yaklaşım mı? Türk Psikoloji Yazıları, 13(26), 45-63.

Kramarski, B. ve Mizrachi, N. (2004). Enhancing Mathematical Literacy With The Use Of Metacognitive Guidance in Forum Discussion, Proceedings of the 28th Conference of The International Group for The Psychology of Mathematics Education, 3, 169-176.

Kuhn, D. (2000). Metacognitive development. Current Directions in Psychological Science, 9(5), 178-181.

Lecce, S., Zocchi, S., Pagnin, A., Palladino, P. ve Taumoepeau, M. (2010). Reading minds: The relation between children's mental state knowledge and their metaknowledge about reading. Child Development, 81, 1876-1893.

Mokhtari, K. ve Reichard, C. A. (2002). Assessing students' metacognitive awareness of reading strategies. Journal of Educational Psychology, 94, 249-259.

Pintrich, P. R. (2002) The role of metacognitive knowledge in learning, teaching, and assessing, Theory into Practice, 41(4), 219-225.

Özsoy, G. (2008). Üstbiliş. Türk Eğitim Bilimleri Dergisi, 6(4), 713-740.

Öztürk, E. (2012). Okuma stratejileri üstbilişsel farkındalık envanterinin Türkçe formunun geçerlik ve güvenirlik çalışması. ilköğretim Online, 11(2), 292-305.

Pereira-Laird, J. A. ve Deane, F. P. (1997). Development and validation of a self-report measure of reading strategy use. Reading Psychology: An International Quarterly, 18, 185-235.

Sarı, S. (2015). ilkokul 4.sınıfta fen bilimleri dersinde üst biliş stratejilerine dayalı öğretim uygulamasının öğrenci erişilerine etkisi. Yayımlanmamış Yüksek Lisans Tezi, Eğitim Bilimleri Enstitüsü, Dumlupınar Üniversitesi, Kütahya.

Schraw, G. ve Dennison, R. (1994). Assessing metacognitive awareness. Contemporary Educational Psychology, 19, 460-475.

Shimamura, A. P. (2008). Handbook of memory and metacognition.In J.Dunlosky \& R. Bjork (Eds), A Neurocognitive Approach to Metacognitive Monitoring and Control(pp. 373390). Erlbaum Publishers: Mahnaw, NJ.

Siswati, B. H. ve Corebima, A. D. (2017). The Effect of Education Level and Gender on Students' Metacognitive Skills in Malang, Indonesia. Advances in Social Sciences Research Journal, 4(4) 163-168.

Sperling, R. A., Howard, B. C. Miller, L. A., ve Murphy, C. (2002). Measures of children's knowledge and regulation of cognition. Contemporary Educational Psychology, 27, 5179.

Sungur, S. ve Şenler, B. (2009). An analysis of Turkish high school students' metacognition and motivation, Educational Research and Evaluation: An International Journal on Theory and Practice, 15(1), 45-62. DOI: 10.1080/13803610802591667.

Şeker, H. ve Gençdoğan, B. (2014). Psikolojide ve Eğitimde Ölçme Aracı Geliştirme. 2. Baskı. Ankara: Nobel Akademi Yayıncılık. 
Tobias, S. ve Everson, H. T. (2002). Knowing What You Know and What You Don't: Further Research on Metacognitive Knowledge Monitoring (Research Report No.2002-3). New York: The College Board.

Yore, L.D. ve Treagust, D.F. (2006). Current Realities and Future Possibilities: Language and science literacy-empowering research and informing instruction. International Journal of Science Education, 28:2-3, 291-314. DOI: 10.1080/09500690500336973.

Veenmann, M. V. J., Van Hout-Wolters, B. ve Afflerbach, P. (2006). Metacognition and learning: Conceptual and methodolgical considerations. Metacognition and Learning, 1, 3-14.

Vrieling, E., Bastiaens, T. ve Stijnen, S. (2012). Effects of increased self-regulated learning opportunities on student teachers' motivation and use of metacognitive skills, Australian Journal of Teacher Education, 37(8), 101-117.

Woolfolk, E.A. (1998). Educational psychology. USA: Allyn Bacon.

Yurdugül, H. (2005). Ölçek geliştirme çalışmalarında kapsam geçerliği için kapsam geçerlik indekslerinin kullanılması. XIV. Ulusal Eğitim Bilimleri Kongresi, Pamukkale Üniversitesi Eğitim Fakültesi, Denizli.

Yürük, N. (2014). Özdüzenlemede üstbiliş. Gönül Sakız (Ed.), Özdüzenleme içinde (s. 28-53). Ankara: Nobel Akademik Yayıncılık.

Young, A. ve Fry, J. D. (2008). Metacognitive awareness and academic achievement in college students. Journal of the Scholarship of Teaching and Learning, 8(2), 1-10. 


\section{SUMMARY}

Metacognition is a concept to think about thought or thought about cognition, which can be defined as the awareness of their own thinking processes and the ability to control these processes (Karakelleve Saraç, 2010; Özsoy, 2008).Metacognition, which is an enhanceable phenomenon related to intelligence, memory, and environmental factors, is a cognitive skills and ability set that involve awareness of the cognitive processes involved in the learning process and the effective use of these processes (Baltacı and Akpınar, 2011).The fact that metacognition is an ability to develop in interaction with the environment has been taken into consideration in the learning and teaching processes. From Flavell, metacognition, which is evaluated within the framework of the theory of the mind, begins to develop as meta-cognitive knowledge from the age of 3 to 5 (Karakelle and Saraç, 2007). Experiences and objectives in regulation skills as other components of metacognition, are lifelong skills that emerge in children 8-10 years old (Kuhn, 2000). Because metacognition helps a person to sense something and control his or her cognitive ability, metacognitive skills should be trained as early as possible. It is therefore necessary for educators to know how to teach and develop their students' metacognitive skills throughout the teaching and learning process (Siswati and Corebima, 2017). In the process of determining how to teach and develop metacognitive skills, it is necessary to measure the metacognitive structures of learners. Thus, in this study, a world widely utilized valid Metacognitive Awareness Scale for Children (A Form) which was developed by Sperling and others., (2002) and adapted into Turkish by Karakelle ve Saraç (2007), is selected as a base for the adaptation study of Teacher Form. Also, the validity and reliability analysis of the scale is aimed within the scope of this study.

Adaptation study of the Metacognitive Awareness Teacher Form was carried out with 6 teachers of 121 students who are studied in the 4th grade of randomly selected primary schools in Istanbul. Within the scope of the research, Form A of the metacognitive awareness scale, which is suitable for 3rd, 4th and 5th grade students, was selected as a base. The final version of the teacher's form has been prepared by taking comments and opinions from the field experts and the cases of consensus and conflicts in the opinion of the expert has been considered to construct the final form. After the expert opinion was received, 15 primary school teachers filled the scale to examine the content validity of the metacognitive awareness teacher form scale and the time required to fill out the scale. After the comments of primary school teachers have been received, the latest version of the scale has been sent to teachers who are in the scope of the study. Within the scope of the validity and reliability studies of the Metacognitive Awareness Scale Teacher Form, first of all, expert opinion was taken from 5 faculty members to ensure the content related validity. The "Metacognitive Awareness Scale for Children" was administered to 31 students in order to test the criterion validity of the scale and the obtained data were tested by Pearson correlation analysis. In order to test the construct validity of the Metacognitive Awareness Scale, explanatory factor analysis was performed. Item total analysis, item discrimination and test-retest analyzes were conducted to test reliability. In order to determine item discrimination of the scale, it was compared with the t-test between the $27 \%$ portion scores of the highest score for each item of the test and the $27 \%$ portion scores of the lowest score for each item of the test. Pearson correlation analysis was also performed to determine the relationship between the test-retest results of 74 students on the Metacognitive Awareness Scale. It was determined that the Metacognitive Awareness Scale, developed when all the findings were evaluated as a result of the research, is a valid and reliable measurement tool that can be used to determine the metacognitive awareness levels of the $3 \mathrm{rd}, 4 \mathrm{th}$ and 5 th grade students in primary school. The evaluation of the metacognition by the teacher is compared with the studies that will be done with the student's own assessment, and investigation the state of differentiation of meta-cognition by empirical studies are suggested. 